ARTICLE

Received 24 Aug 2015 | Accepted 1 Feb 2016 | Published 8 Mar 2016

DOI: $10.1038 /$ ncomms10909

OPEN

\title{
Cadherin-11 localizes to focal adhesions and promotes cell-substrate adhesion
}

\author{
Rahul P. Langhe ${ }^{1, \dagger}$, Tetyana Gudzenko ${ }^{2}$, Michael Bachmann ${ }^{3}$, Sarah F. Becker ${ }^{1, \dagger}$, Carina Gonnermann ${ }^{2}$, \\ Claudia Winter ${ }^{1}$, Genevieve Abbruzzese ${ }^{4}$, Dominique Alfandari ${ }^{4}$, Marie-Claire Kratzer ${ }^{1,5}$, Clemens M. Franz ${ }^{2}$ \\ $\&$ Jubin Kashef ${ }^{1,6}$
}

Cadherin receptors have a well-established role in cell-cell adhesion, cell polarization and differentiation. However, some cadherins also promote cell and tissue movement during embryonic development and tumour progression. In particular, cadherin-11 is upregulated during tumour and inflammatory cell invasion, but the mechanisms underlying cadherin-11 stimulated cell migration are still incompletely understood. Here, we show that cadherin-11 localizes to focal adhesions and promotes adhesion to fibronectin in Xenopus neural crest, a highly migratory embryonic cell population. Transfected cadherin-11 also localizes to focal adhesions in different mammalian cell lines, while endogenous cadherin-11 shows focal adhesion localization in primary human fibroblasts. In focal adhesions, cadherin-11 co-localizes with $\beta 1$-integrin and paxillin and physically interacts with the fibronectin-binding proteoglycan syndecan-4. Adhesion to fibronectin mediated by cadherin-11/syndecan-4 complexes requires both the extracellular domain of syndecan-4, and the transmembrane and cytoplasmic domains of cadherin-11. These results reveal an unexpected role of a classical cadherin in cell-matrix adhesion during cell migration.

\footnotetext{
${ }^{1}$ Zoological Institute, Cell and Developmental Biology, Karlsruhe Institute of Technology (KIT), Kaiserstrasse 12, 76131 Karlsruhe, Germany. ${ }^{2}$ Center for Functional Nanostructures, Karlsruhe Institute of Technology (KIT), Wolfgang-Gaede-Strasse 1a, 76131 Karlsruhe, Germany. ${ }^{3}$ Zoological Institute, Cell and Neurobiology Biology, Karlsruhe Institute of Technology (KIT), Haid-und-Neu-Strasse 9, 76131 Karlsruhe, Germany. ${ }^{4}$ Department of Veterinary and Animal Sciences, University of Massachusetts, Amherst, Massachusetts 01003, USA. ${ }^{5}$ Laboratory for Applications of Synchrotron Radiation, Karlsruhe Institute of Technology (KIT), Engesser Straße 15, 76131 Karlsruhe, Germany. ${ }^{6}$ Institute for Photon Science and Synchrotron Radiation, Karlsruhe Institute of Technology (KIT), Hermann-von-Helmholtz-Platz 1, 76344 Eggenstein-Leopoldshafen, Germany. † Present addresses: Institute of Neuroscience Paris-Saclay, UMR CNRS 9197, Université Paris-Sud, Orsay, France (R.P.L.); Institut de Génétique et de Biologie Moléculaire et Cellulaire (IGBMC), CNRS UMR7104, INSERM U964, Université de Strasbourg, 1 rue Laurent Fries, 67404 IIlkirch Cu Strasbourg, France (S.F.B.). Correspondence and requests for materials should be addressed to C.M.F. (email: clemens.franz@kit.edu) or to J.K. (email: jubin.kashef@kit.edu).
} 
D uring embryonic development cell adhesion is not only important to maintain tissue morphogenesis and homeostasis, it is also crucial for processes such as cell migration, cell signalling and wound healing ${ }^{1-4}$. Importantly, dysregulation of adhesion molecules often causes developmental disorders and various diseases, including cancer and inflammation ${ }^{5}$. Cadherins represent a multigene family of $\mathrm{Ca}^{2+}$-dependent glycoproteins mediating homophilic cell-cell adhesion. Apart from forming robust cell-cell contacts, cadherins are known to initiate different intracellular signalling cascades and to modulate cell cortex tension ${ }^{6,7}$. Furthermore, different cadherins have been shown to promote cell migration ${ }^{5}$. In particular, the mesenchymal cadherin-11 promotes cell migration in different cell types. In humans, for instance, upregulation of cadherin-11 correlates with tumour progression and inflammatory arthritis ${ }^{8-11}$. During development cadherin-11 is also expressed in cranial neural crest cells (NCCs), a highly motile and multipotent stem-cell population giving rise to a variety of different cell types of the vertebrate face and head including cartilage, bone and ganglia ${ }^{12,13}$. In Xenopus, it was recently demonstrated that transient cadherin-11-mediated cell-cell adhesion is crucial for proper NCC cell migration in the context of contact inhibition of locomotion, an important mechanism for the directional migration of $\mathrm{NCC}^{14}$. Depletion of the homophilic adhesive function of cadherin-11 results in higher invasiveness of NCC and non-directional and incomplete NCC migration due to loss of contact inhibition of locomotion ${ }^{15}$. Furthermore, knockdown analysis revealed that cadherin-11 initiates filopodia and lamellipodia formation in vivo upstream of the guanine exchange factor Trio and small GTPases ${ }^{16}$. Interestingly, cadherin-11 morphant NCC lose leading edge and rear polarity, and exhibit cell rounding and membrane blebbing instead of forming cell protrusions ${ }^{16}$. The non-spreading and blebbing phenotype of the cadherin-11-deficient NCC raises the intriguing possibility that normally cadherin-11 plays an important role in mediating cell-substrate adhesion in migrating NCC, in addition to its classical cell-cell adhesion function.

In this study we demonstrate that cadherin-11 co-localizes with $\beta 1$-integrin and paxillin to focal adhesions (FAs) in Xenopus NCC, where it promotes cell adhesion to fibronectin. We furthermore show that cadherin-11 also localizes to FAs in different human and murine cell lines, together with known FA markers such as paxillin, vinculin, FAK, VASP and F-actin. Moreover, cadherin-11 physically interacts with the heparan sulfate proteoglycan syndecan-4, and this interaction is required for cadherin-11-mediated adhesion to fibronectin. In rescue experiments, we furthermore demonstrate that the extracellular domain of syndecan-4, which mediates adhesion to fibronectin, and the transmembrane as well as the cytoplasmic domain of cadherin-11 are needed for proper NCC spreading and cell-matrix adhesion.

\section{Results}

Cadherin-11 localizes to FAs. Cadherin-11 is a classical cadherin adhesion receptor localizing to cell-cell contacts in a variety of cell types. In Xenopus, expression of cadherin-11 (Xcad-11) coincides with the onset of NCC migration, pointing to an additional migration-related property of Xcad-11 (refs 12,16). In agreement, we previously observed Xcad-11 localization to cell protrusions in migrating $\mathrm{NCC}^{16}$. To investigate a potential role of Xcad-11 in cell migration in more detail, we explanted Xcad-11EGFP-injected Xenopus NCC on a fibronectin substrate and analysed the subcellular localization of Xcad-11 by confocal laser scanning microscopy. As expected, Xcad-11 localized to cell-cell contacts together with the adherens junction marker $\beta$-catenin (Fig. 1a). However, in addition to the apical localization at cell-cell contacts, Xcad-11 also displayed striking localization to the cell-substrate interface of NCC, as visualized by total internal reflection fluorescence (TIRF) microscopy (Fig. 1b,c). Here, Xcad-11 co-localized with paxillin (Fig. 1b) and $\beta 1$-integrin (Fig. 1c) in FAs predominately at the cell periphery. These results revealed a surprising localization of a classical cadherin protein to cell-matrix contacts.

Overexpression of GFP fusion proteins can lead to aberrant subcellular localization relative to the endogenous protein. Currently there are no antibodies available for immunostaining of Xcad-11, preventing direct analysis of endogenous Xcad-11 localization in NCC. To control the potential overexpression artefacts, we re-expressed Xcad-11 at physiological levels in an Xcad-11 knockdown background. For this we co-injected an Xcad-11 antisense morpholino oligonucleotide (MO) and an Xcad-11 myc-tagged (Xcad-11-myc) rescue construct at $500 \mathrm{pg}$. In a previous titration series, we had observed full in vivo NCC migration at this injection dose (data not shown), indicating re-establishment of physiological Xcad-11 levels. Immunostaining against the myc-tag on explanted NCC confirmed Xcad-11 localization to FAs together with paxillin (Supplementary Fig. 1a), in agreement with our results with Xcad-11-EGFP-injected NCC.

To examine whether the atypical FA localization of Xcad-11 also occurs in other cell types, we analysed the localization of endogenous cadherin-11 in human foreskin fibroblast (HFF-1) cells. Again, we observed cadherin-11 co-localizing with paxillin in FAs (Supplementary Fig. 1b). Interestingly, a recent proteomics analysis also identified cadherin-11 as a FA component in HFF-1 cells $^{17}$. In addition, transfection of Xcad-11-EGFP into HeLa (cervical cancer cells), MCF-7 (breast cancer cells) and murine NIH 3T3 fibroblasts revealed Xcad-11 localization to peripheral FA, where it co-localized with paxillin and F-actin (Fig. 1d; Supplementary Fig. 2). Likewise, HeLa cells co-transfected with Xcad-11-EGFP and vinculin-mCherry showed co-localization of both proteins at FAs (Supplementary Fig. 2a). Time-lapse fluorescence microscopy of HeLa cells showed association of Xcad-11-EGFP with newly forming FAs (Supplementary Movie 1). Kymographs generated across newly forming FA sites revealed that Xcad-11 recruitment frequently preceded vinculin recruitment (Supplementary Fig. 3), suggesting a role of Xcad-11 in the initiation of FA formation. The fluorescence still and timelapse images also indicated partially overlapping yet distinct localization patterns of Xcad-11 and paxillin or vinculin within FAs in the mammalian cell lines. Although Xcad-11 usually localized to the distal end of FA, vinculin and paxillin typically localized to a more proximal position, with Xcad-11 and the FA markers co-localizing in the central FA region. The localization pattern of Xcad-11 at cell-matrix adhesion sites was furthermore analysed at higher resolution by structured illumination microscopy (SIM). The SIM images and intensity profile analysis confirmed partially overlapping patterns of Xcad-11 and paxillin, vinculin, FAK, VASP and zyxin within FAs (Supplementary Fig. 4). Again, Xcad-11 typically located more distally in FAs towards the cell margin, whereas paxillin, vinculin, FAK, VASP and zyxin accumulated more proximally (Supplementary Fig. 4). Xcad-11 also frequently displayed a punctate localization pattern not seen by conventional fluorescence microscopy.

Next, we asked whether other classical cadherins, such as $\mathrm{N}$-cadherin or C-cadherin, also localize to FAs besides Xcad-11. We therefore examined the subcellular localization of endogenous $\mathrm{N}$-cadherin together with paxillin in HFF-1 cells. As expected, $\mathrm{N}$-cadherin localized to cell-cell contact sites, but not in FAs as demonstrated by TIRF microscopy (Supplementary Fig. 1c). We also transfected N-cadherin-GFP and C-cadherin-GFP into HeLa cells and immunostained against endogenous vinculin. 
Both N-cadherin and C-cadherin localized to cell-cell contact sites, but not to FAs (Supplementary Fig. 1d,e), indicating that FA localization is a unique property of Xcad-11 among classical cadherins. Since classical cadherins are dynamically linked via $\beta$-catenin and $\alpha$-catenin to the actin cytoskeleton, we next asked whether Xcad-11 also localizes with $\beta$-catenin in FA. HeLa cell transfected with Xcad-11-EGFP and immunostained against endogenous $\beta$-catenin displayed a prominent co-localization of Xcad-11-EGFP and $\beta$-catenin at cell-cell contact sites but also in FAs (Supplementary Fig. 5). Our results are in agreement with a recent proteomics analysis identifying $\beta$-catenin and $\alpha$-catenin as FA components in HFF-1 cells ${ }^{17}$. Interestingly, $\beta$-catenin localization to FAs requires Xcad-11 expression, since untransfected HeLa cells contain no $\beta$-catenin in cell-matrix sites. These findings support the important role of Xcad-11 in promoting cell-matrix adhesion via catenin-based linkage to the actin cytoskeleton.

FA are sites of closest cell-matrix contact. To further demonstrate Xcad-11 localization to FAs at the cell-substrate interface, adherent HeLa cells expressing Xcad-11-EGFP were inverted $^{18}$ and basal cell surfaces were imaged by atomic force microscopy (AFM). Xcad-11-EGFP positive regions corresponded to areas of locally increased height on the basal side, indicating that Xcad-11 localized to sites of close cell-substrate contact (Supplementary Fig. 6a). The increased Xcad-11-EGFP fluorescence signal at sites of closest cell-substrate contact indicated specific cadherin recruitment, rather than locally increased plasma membrane accumulation, as a general plasma membrane marker (GAP43-mcherry) displayed homogenous localization throughout basal cell membranes in TIRF microscopy images (Supplementary Fig. 6a' ${ }^{\prime \prime \prime}$ ).
To furthermore investigate whether Xcad-11 localization to FAs was specific for fibronectin substrates, HeLa cells were transfected with Xcad-11-EGFP and cultured on microstructured substrates featuring alternating fibronectin/laminin or fibronectin/BSA stripes. Xcad-11-EGFP positive FAs formed selectively on fibronectin stripes, but not on the neighbouring laminin or BSA stripes (Supplementary Fig. 6b). Specific recruitment of Xcad-11 to fibronectin-induced FA sites may explain why Xcad-11 stimulates NCC migration on fibronectin ${ }^{19}$.

Xcad-11 promotes FA formation and adhesion. Xcad-11 localization at the cell-substrate interface pointed towards a functional role of Xcad-11 in FA formation and/or cell-substrate adhesion. To test this hypothesis, Xenopus embryos were injected with control or Xcad-11 antisense MO. NCC were then explanted on fibronectin-coated dishes, fixed and immunostained for paxillin or for phosphopaxillin, a marker for active FA turnover ${ }^{20}$. Control MO injected NCC spread on fibronectin, formed cell protrusions and showed paxillin and phosphopaxillin staining in FAs at the leading edge (Fig. 2a; Supplementary Fig. 7). In contrast, Xcad-11 morphant NCC displayed only diffuse paxillin staining in the cytoplasm and in blebs and a complete loss of phosphopaxillin (Fig. 2a; Supplementary Fig. 7). Furthermore, Xcad-11 morphant NCC lost the ability to form cell protrusions and instead rounded-off and displayed a blebbing phenotype, consistent with our previous in vivo results demonstrating that Xcad-11-initiated cell protrusions are essential for proper NCC spreading and migration ${ }^{16}$. Co-injection of full-length Xcad-11, however, rescued paxillin and phosphopaxillin staining, further supporting a role of Xcad-11 in FA formation (Fig. 2a).
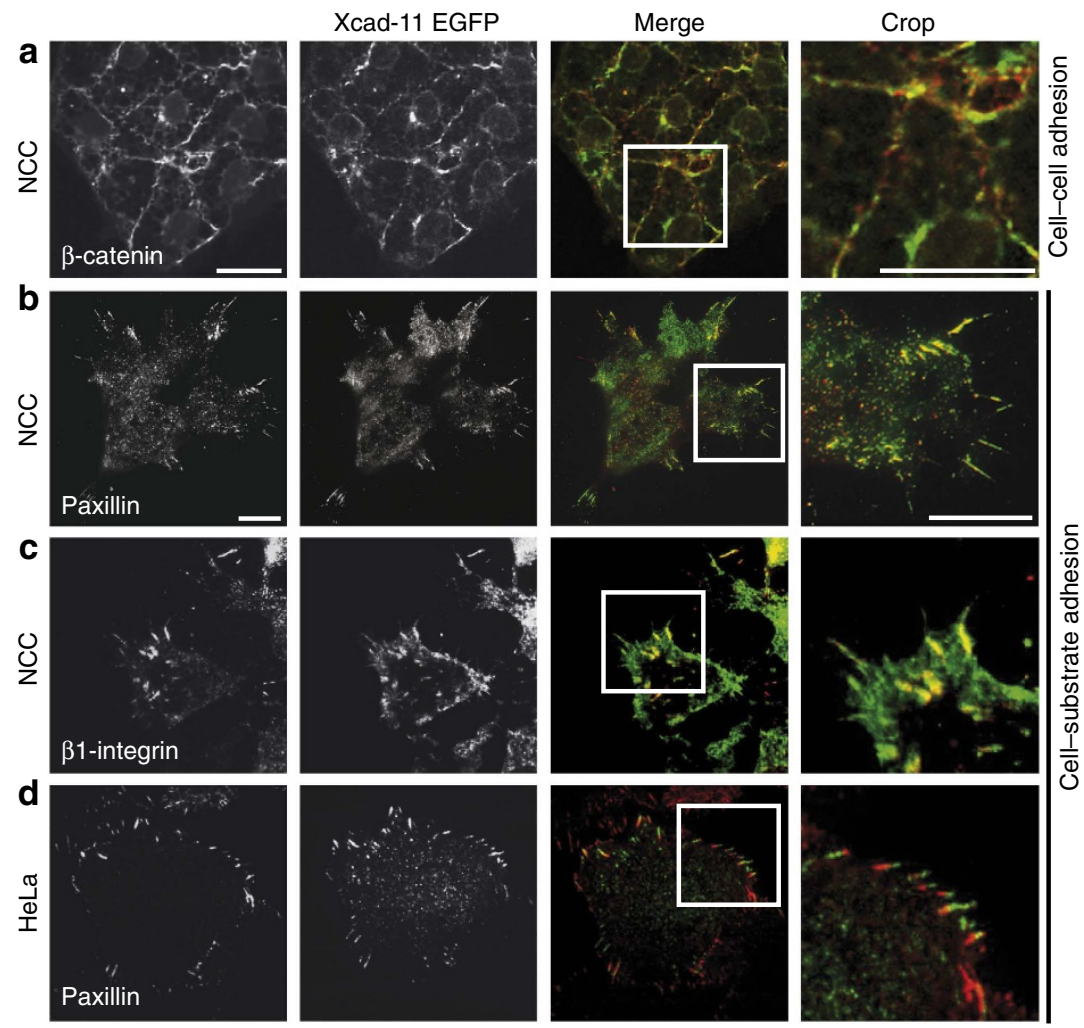

Figure 1 | Xcad-11 is localized in focal adhesions. Xenopus NCC injected with Xcad-11-EGFP, explanted on fibronectin-coated glass dishes and immunostained for (a) $\beta$-catenin, (b) paxillin and (c) $\beta 1$-integrin. (a) A confocal image focused on the apical side of NCC shows co-localization of Xcad-11 with $\beta$-catenin at cell-cell contacts. (b,c) TIRF images demonstrating co-localization of Xcad-11 with paxillin and $\beta 1$-integrin in focal adhesions at the cell substrate. (d) HeLa cells transfected with Xcad-11-EGFP, immunostained for paxillin and imaged by TIRF microscopy display partial localization of Xcad-11 with paxillin at the cell substrate. Scale bars, $20 \mu \mathrm{m}$ (a); $10 \mu \mathrm{m}$ (b-d). 
a
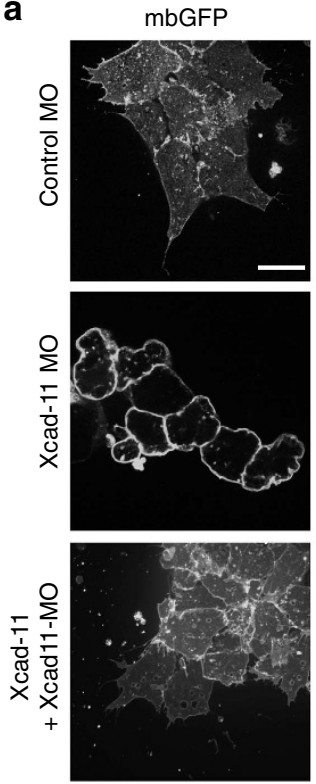

Phosphopaxillin
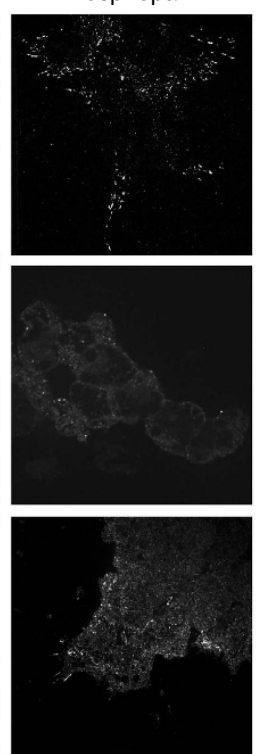

Merge
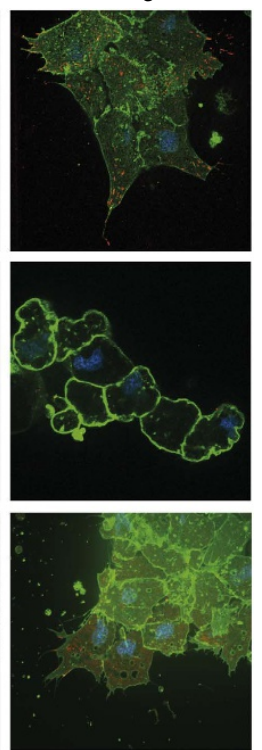

b
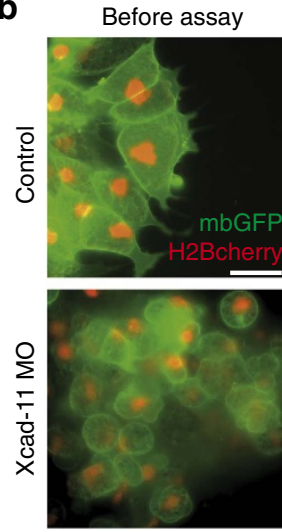

$\mathbf{e}$

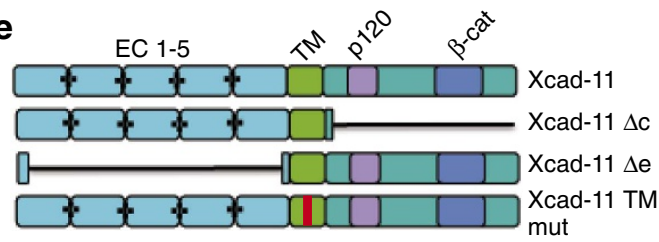

C

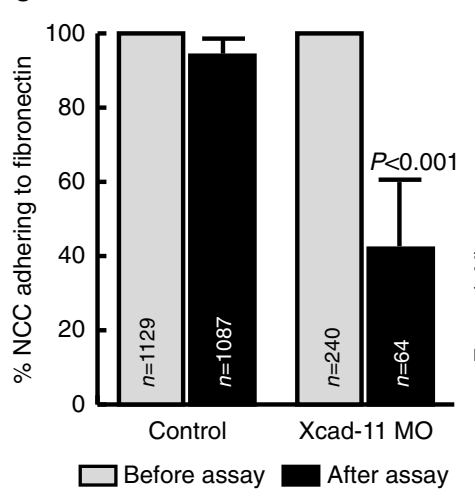

d

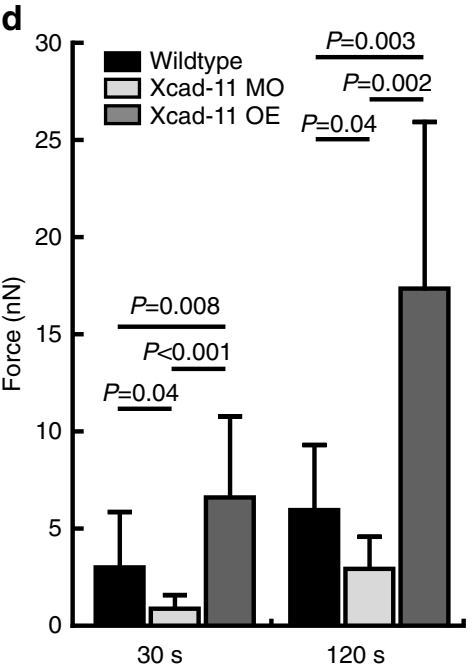

f

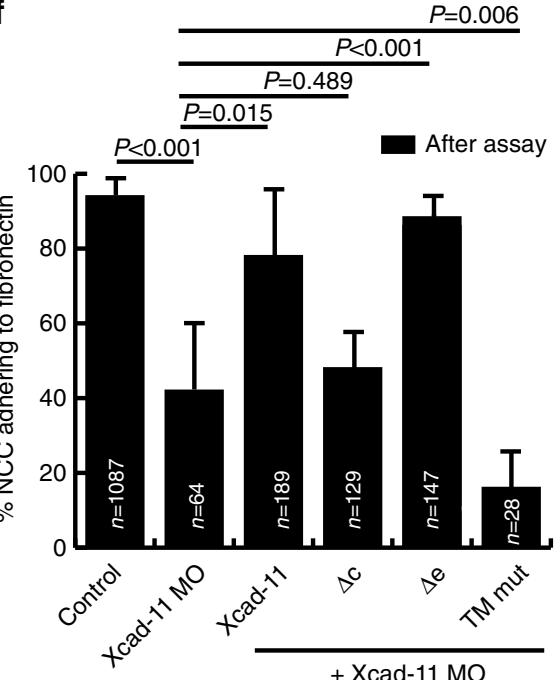

Figure 2 | Xcad-11 promotes focal adhesion formation and cell-substrate adhesion. (a) NCC explants injected with mbGFP and immunostained for phosphopaxillin. Depletion of Xcad-11 by MO injection leads to loss of phosphopaxillin staining. (b) NCC injected with mbGFP and H2B-cherry or together with Xcad-11 MO. Fluorescence images collected at the same substrate position before (right column) and after (left column) the flipping assay. (c) Statistics for flipping assay (mean \pm s.d.), $n=$ total number of cells before and after flipping assay. Results of at least three independent experiments were averaged and statistical significance was analysed by Student's $t$-test. (d) Adhesion forces (mean \pm s.d.) measured by AFM-based SCFS. At least 10 different cells were measured per condition and statistical significance was assessed according to the Mann-Whitney test. (e) Xcad-11 constructs for reconstitution: extracellular (EC), transmembrane (TM); (p120/ $\beta$-cat) p120-binding or $\beta$-cat-binding site. (f) Statistics for reconstitution (mean \pm s.d.), $n=$ total number of cells after flipping assay. Scale bars, $20 \mu \mathrm{m}$.

A potential function of Xcad-11 in cell-substrate adhesion was analysed using a specific flipping assay (see Methods). Wild-type NCC injected with mbGFP (to label the plasma membrane) and H2B-cherry (to label nuclei) displayed strong adhesion to fibronectin, as $94 \%$ of NCC remained on the fibronectin substrate after flipping (Fig. 2b,c). In contrast, Xcad-11 MO-injected NCC showed strongly reduced adhesion (42\% after flipping, Fig. 2b,c). Since flipping assays only provide semi-quantitative results, cell adhesion was also quantitated by AFM-based single-cell force spectroscopy (SCFS, Fig. 2d). For contact times $\geq 10 \mathrm{~s}$, adhesion forces generated by Xcad-11 morphant cells were significantly lower compared with wild-type cells, while overexpression of Xcad-11 significantly increased adhesion forces generated over wild-type NCC levels (Fig. 2d). Together, these results underline the important role of Xcad-11 in mediating FA formation and cell-substrate adhesion and suggested that Xcad-11 directly promotes adhesion to fibronectin.

We therefore sought to identify Xcad-11 domains essential for promoting cell-substrate adhesion. Classical cadherins contain three different functional domains. The extracellular part mediates cell-cell adhesion through homophilic binding 21 , while the transmembrane domain is important for lateral cadherin interactions ${ }^{22}$ or interactions with other transmembrane proteins ${ }^{23}$. The cytoplasmic tail of cadherins contains binding sites for different catenin proteins such as p120-catenin, which regulates adhesion complex assembly ${ }^{24}$ and 
lateral cadherin clustering ${ }^{25,26}$, and $\beta$-catenin, which dynamically anchors cadherins to the actin cytoskeleton via $\alpha$-catenin ${ }^{27}$ and also interacts with vinculin ${ }^{28}$. To investigate the contribution of these three domains to adhesion, we designed different Xcad-11 deletion mutants as myc-tagged constructs and tested their rescue ability in the flipping assay. Before performing flipping assays, we verified proper cell-surface expression of all injected myc-tag constructs by immunostaining in Xenopus animal cap explants: all deletion mutants co-localized with $\beta$-catenin at the plasma membrane (Supplementary Fig. 8). In the flipping assay, Xcad-11 lacking the cytoplasmic tail $(\Delta c)$ failed to rescue NCC adhesion and spreading on fibronectin (Fig. 2f; Supplementary Fig. 9), showing that the extracellular cell-cell adhesion domain of
Xcad-11 alone is insufficient for cell-substrate adhesion. In contrast, Xcad-11 lacking the extracellular domain $(\Delta \mathrm{e})$ displayed even higher rescue efficiency than full-length Xcad-11 (Fig. 2f), demonstrating that a direct interaction between the Xcad-11 extracellular domain and fibronectin is not required for promoting cell-substrate adhesion. The significant rescue ability of the $\Delta \mathrm{e}$ mutant agrees with previous observations that this mutant enhances NCC migration on fibronectin ${ }^{16,29}$. To complement the adhesion assay, we analysed the subcellular localization of the $\Delta \mathrm{e}$-EGFP and $\Delta \mathrm{c}$-EGFP constructs in MCF-7 cells. The $\Delta$ e-EGFP mutant was often enriched at the cell edge, where it displayed the typical localization to the distal part of peripheral FAs as observed for full-length Xcad-11-EGFP, or it
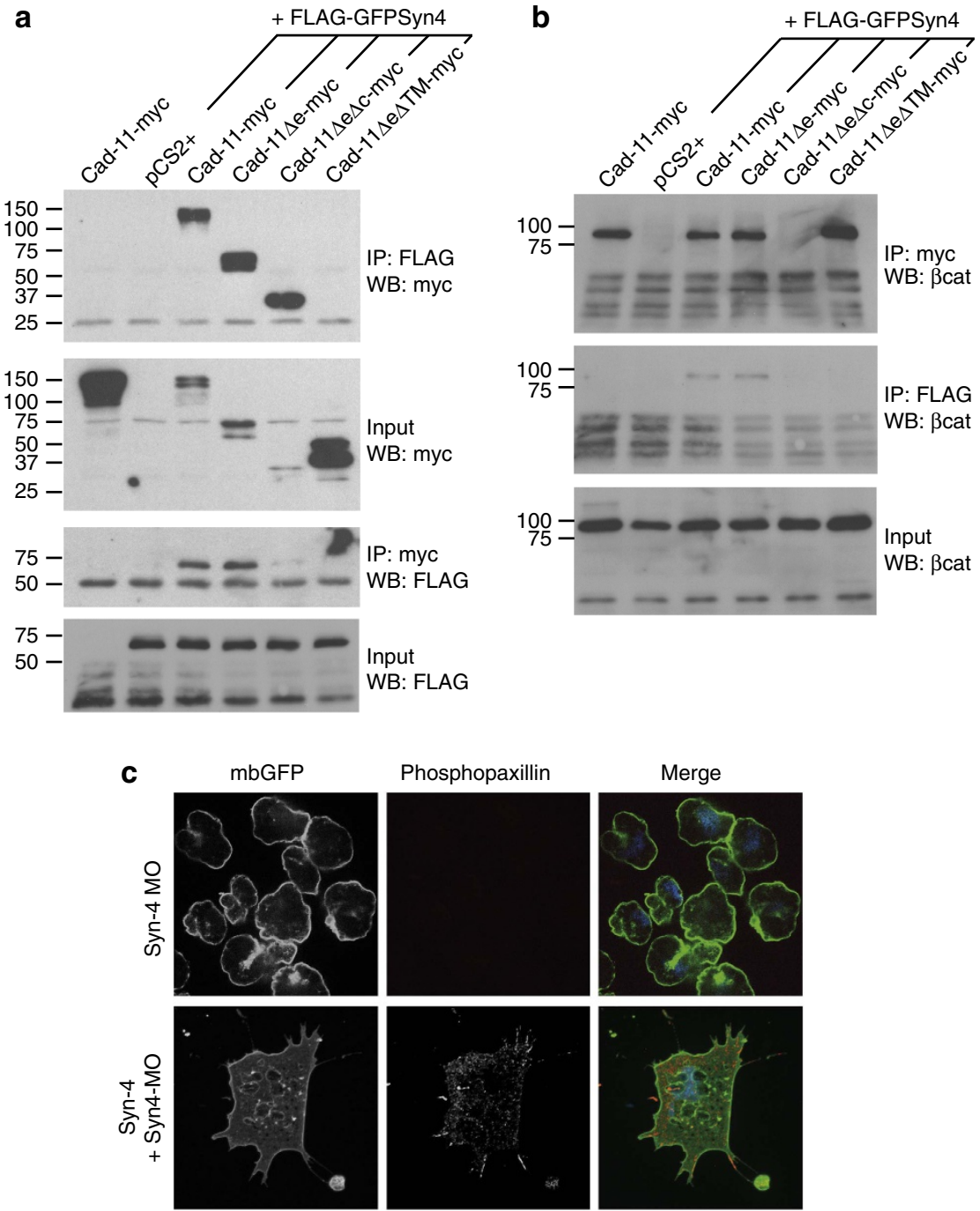

Figure 3 | Syn-4 interacts with Xcad-11 and stimulates focal adhesion formation. (a) Co-immunoprecipitation of Syn-4 with different Xcad-11 constructs. (First row) Precipitation of Syn-4 with FLAG antibody from transfected HEK293 cells. Western blot for Xcad-11 (myc) showed successful co-precipitation of Xcad-11, Xcad-11 $\Delta \mathrm{e}$ and Xcad-11 $\Delta \mathrm{e} \Delta \mathrm{c}$. In the case of Xcad-11 $\Delta \mathrm{e} \Delta \mathrm{TM}$ and pCS2 +, no co-precipitation with Syn-4 was detected. (Second row) Input for the different Xcad-11 constructs was detected by western blotting. (Third row) Precipitation of different Xcad-11 constructs with myc antibody from transfected HEK293 cells. Western blot for Syn-4 (FLAG) showed successful co-precipitation of Xcad-11, Xcad-11 $\Delta$ e and Xcad-11 $\Delta$ e $\Delta$ c. In the case of Xcad-11 $\Delta$ e $\Delta T M$ and pCS2 +, no co-precipitation with Syn-4 was detected. (Fourth row) Input for Syn-4 was detected by western blotting. Transfection of Xcad-11 alone served as negative control (first panel). (b) Co-immunoprecipitation of Syn- 4 with different Xcad-11 constructs analysed for $\beta$-catenin ( $\beta$ cat) binding. (First row) Precipitation of different Xcad-11 constructs with myc antibody from transfected HEK293 cells. Western blot for $\beta$ cat showed successful co-precipitation of Xcad-11, Xcad-11 $\Delta \mathrm{e}$ and Xcad-11 $\Delta \mathrm{e} \Delta \mathrm{TM}$. In the case of Xcad-11 $\Delta \mathrm{e} \Delta \mathrm{c}$ and $\mathrm{pCS} 2+$, no co-precipitation with $\beta c a t$ was detected. (Second row) Precipitation of Syn-4 with FLAG antibody showed successful co-precipitation of $\beta$ cat when Xcad-11 or Xcad-11 $\Delta$ e were co-transfected. (Third row) Input for $\beta c$ at was detected by western blotting. Transfection of Xcad-11 alone served as negative control (first panel). (c) NCC explants co-injected with mbGFP and Syn-4 MO and immunostained for phosphopaxillin. Depletion of Syn-4 leads to loss of phosphopaxillin staining, which is rescued by co-injection of Syn-4. Scale bars, $20 \mu \mathrm{m}$. 
localized in vesicles (Supplementary Fig. 10a). In contrast, $\Delta \mathrm{c}$-EGFP showed a fully homogeneous distribution throughout the cell without accumulation at FA sites, suggesting that the extracellular domain of Xcad-11 is not required for localization to FAs (Supplementary Fig. 10b). The transmembrane domain of different classical cadherins contains protein-protein interaction sequence-binding sites and some of these interactions can be disrupted by double-point mutations. For instance, in N-cadherin the double-point mutation significantly reduces its affinity to $\operatorname{arcadlin}^{23}$. In analogy, we mutated the corresponding amino acids in Xcad-11 (V506P and L507G, Xcad-11 TM mut, Fig. 2e) and analysed the rescue capacity of this construct in the flipping assay. Co-injection of Xcad-11 TM mut and Xcad-11 MO caused a more severe loss of cell-substrate adhesion compared with Xcad-11 MO alone (Fig. 2f; Supplementary Fig. 9). This suggests an important role of the Xcad-11 transmembrane domain in mediating cell-substrate adhesion. To exclude overexpression artefacts of the different Xcad-11 deletion constructs, we also injected each construct alone in wild-type Xenopus embryos at the same concentration used for the Xcad-11 MO rescue experiments. In situ hybridization for the NCC-specific marker AP2 revealed that none of the injected deletion constructs blocks NCC migration in vivo (Supplementary Fig. 11a,b). Furthermore, all injected NCC spread normally and formed cell protrusions when explanted onto fibronectin (Supplementary Fig. 11a). In addition, overexpression of Xcad-11-EGFP did not disturb NCC migration and cell morphology (Supplementary Fig. 11a,b).

Xcad-11 interacts with Syndecan-4. There is no evidence that cadherins mediate fibronectin binding directly, but Xcad-11 may promote cell-substrate adhesion by interacting with a bona fide a
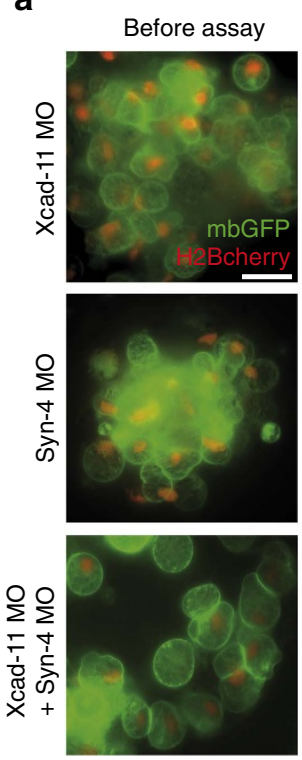

b

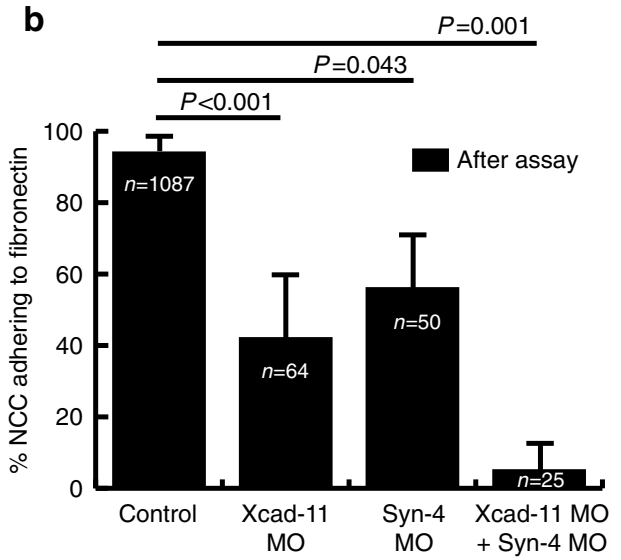

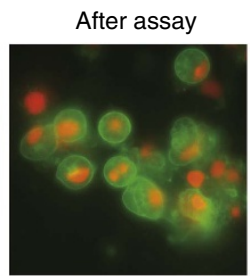
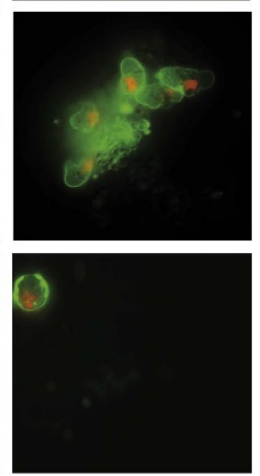
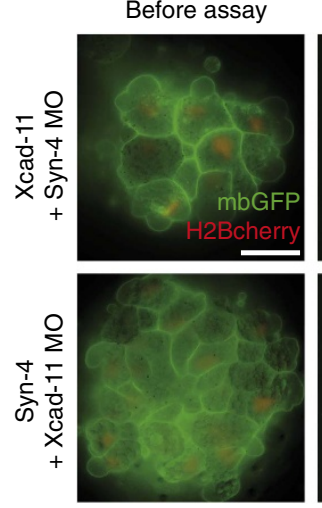

After assay
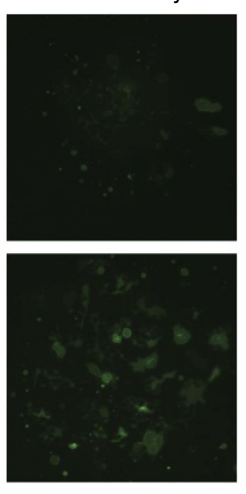

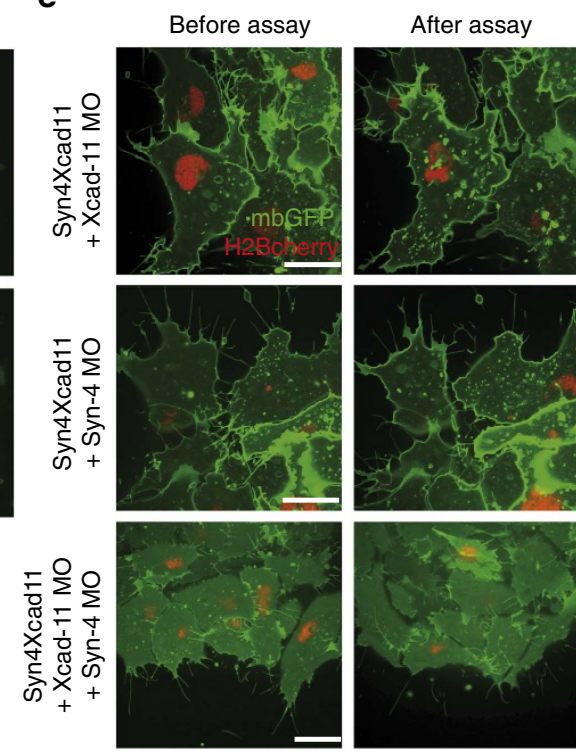

e d

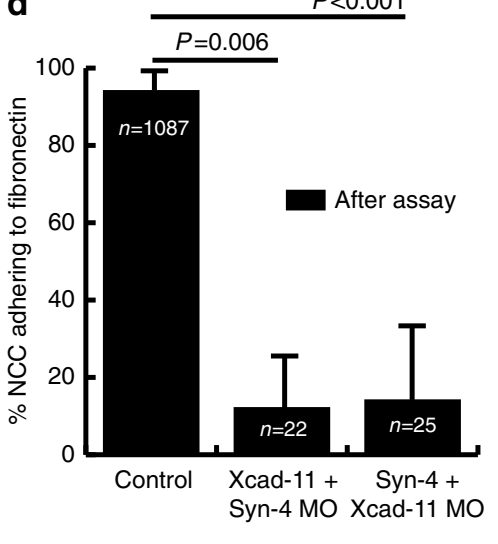

$\mathbf{f}$
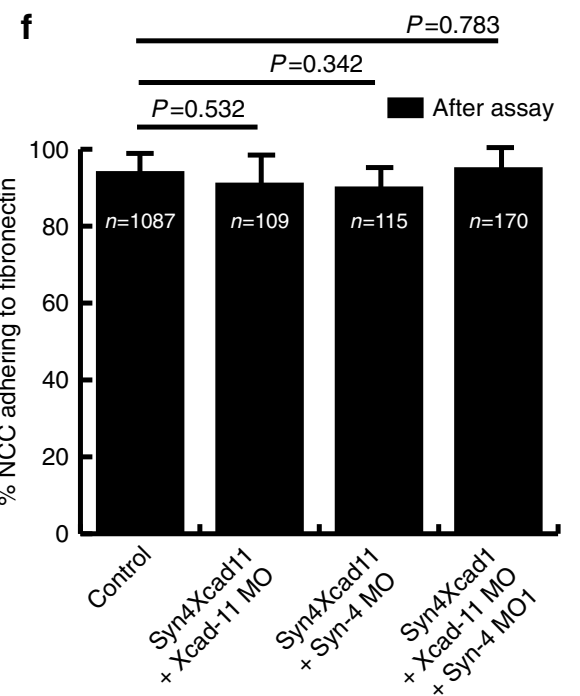

Figure 4 | Synergistic function of Xcad-11 and Syn-4 in mediating cell-substrate adhesion. (a,c,e) NCC explants co-injected with mbGFP, H2Bcherry and indicated constructs before (right column) and after (left column) the flipping assay. (b,d,f) Statistics for flipping assays corresponding to a,c and $\mathbf{e}$, respectively (mean \pm s.d.), $n=$ total number of cells after flipping assay. Results of at least three independent experiments were averaged and statistical significance was analysed by Student's t-test. (a,b) Depletion of both Xcad-11 and Syn-4 leads to a dramatic loss of cell-substrate adhesion. (c,d) Neither co-injection of Xcad-11 nor Syn-4 rescues depletion of Syn-4 or Xcad-11, respectively. (e,f) Co-injection of chimera construct Syn4Xcad11 (Syn-4 EC domain and Xcad-11 TM as well as cytoplasmic domain) rescues cell-substrate adhesion in all NC morphant cells. Scale bars, $20 \mu \mathrm{m}$. 
fibronectin receptor. Syndecan-4 (Syn-4) binds fibronectin and together with integrins stabilizes FA sites ${ }^{30}$. Syn- 4 is expressed in Xenopus NCC and promotes directional migration of these cells $^{31}$, and could hence act as a co-receptor for Xcad-11. To test this hypothesis, we first analysed whether Xcad-11 forms a complex and co-immunoprecipitates with Syn-4. Full-length Xcad-11 and the extracellular deletion mutant $\Delta \mathrm{e}$ were both in complex with Syn-4 (Fig. 3a). To further elucidate whether the transmembrane or the cytoplasmic domain of the $\Delta \mathrm{e}$ construct interacts with Syn-4, we designed two further deletion constructs either containing the cytoplasmic $(\Delta \mathrm{e} \Delta \mathrm{TM})$ or the transmembrane domain alone ( $\Delta \mathrm{e} \Delta \mathrm{c}$, Supplementary Fig. 12a). Interestingly, the $\Delta \mathrm{e} \Delta \mathrm{c}$ construct interacts with Syn-4, whereas the soluble cytoplasmic domain of Xcad-11 $(\Delta \mathrm{e} \Delta \mathrm{TM})$ does not bind (Fig. 3a). We obtained the same results when we reverse co-immunoprecipitated with Xcad-11 instead of Syn-4, indicating that Syn-4 and Xcad-11 form a stable complex (Fig. 3a). Classical cadherins interact with $\beta$-catenin, which dynamically anchors cadherins to the actin cytoskeleton via $\alpha$-catenin ${ }^{27}$. We performed additional co-immunoprecipitation experiments to test whether $\beta$-catenin is also part of Xcad-11/Syn- 4 complexes. First, we examined whether Syn-4 alone interacts with and co-immunoprecipitates $\beta$-catenin. In the absence of Xcad-11, Syn-4 did not co-immunoprecipitate with $\beta$-catenin. However, co-transfection of full-length Xcad-11 or the $\Delta \mathrm{e}$ construct together with Syn- 4 recruited $\beta$-catenin to Syn- 4 complexes. This interaction requires both the transmembrane and the cytoplasmic domain containing the $\beta$-catenin-binding site of Xcad-11, since co-transfection of $\Delta \mathrm{e} \Delta \mathrm{TM}$ and $\Delta \mathrm{e} \Delta \mathrm{c}$ did not cause co-immunoprecipitation of $\beta$-catenin (Fig. 3b). Taken together, these experiments identify the Xcad-11 transmembrane domain as a binding site for Syn- 4 and a joint role of the transmembrane and cytoplasmic domain of Xcad-11 in promoting cell-substrate adhesion.

Syn-4/Xcad-11 interaction promotes adhesion to fibronectin. Next we determined whether Syn-4 promotes FA formation and cell-substrate adhesion in NCC. Indeed, Syn-4 morphant NCC were unable to spread on fibronectin and formed blebs instead of cell protrusions. Furthermore, Syn-4 MO-injected NCC displayed diffuse cytoplasmic paxillin staining, as well as a complete loss of phosphopaxillin staining, similar to Xcad-11 MO cells. All defects however, could be rescued by co-injection of Syn-4 in Syn-4morphant NCC (Fig. 3c; Supplementary Fig. 7). In addition, loss of Syn-4 reduced cell-substrate adhesion (Fig. 4a,b). As knockdown of either Syn-4 or Xcad-11 resulted in a similar loss of FA formation and cell-substrate adhesion, both proteins appear to act synergistically in mediating NCC adhesion. Indeed, simultaneous loss of both proteins led to a dramatic loss of cell-substrate adhesion compared with the individual morpholino knockdowns (Fig. 4a,b). Interestingly, co-injection of Syn-4 in Xcad-11 morphants, or vice versa, did not rescue cell-substrate adhesion, indicating that both proteins act at an equal hierarchical level (Fig. 4c,d).

An equal contribution of Syn- 4 and Xcad-11 in mediating NCC adhesion to fibronectin could indicate that (1) Xcad-11 and Syn-4 act independently or (2) that both proteins are in the same complex and promote adhesion to fibronectin together. To test the second hypothesis we generated a chimera construct (Syn4Xcad11) consisting of the Syn-4 extracellular domain and the transmembrane and cytoplasmic domains of Xcad-11 (Supplementary Fig. 11b). The extracellular domain of Syn-4 contains heparan sulfate chains, which are important for binding to extracellular matrix proteins such as fibronectin ${ }^{32,33}$. Strikingly, co-injection of the chimera construct rescued cell-substrate adhesion in Xcad-11, Syn-4 and double-morphant
NCC cells (Fig. 4e,f). Hence, the extracellular domain of Syn-4 may promote direct adhesion to fibronectin, whereas the cytoplasmic domain of Xcad-11 could link the Syn4/Xcad-11 complex to cytoskeleton adapters at FAs. However, Syn4Xcad11myc and Syn-4-GFP display a homogenous distribution throughout the basal cell membrane, including at FAs, but not exclusively so (Supplementary Fig. 13). Thus, the Syn4Xcad11 chimera and full-length Syn-4-GFP may share a similar localization mechanism that is not predominately targeted to FAs. It is therefore unclear whether the interaction between Xcad11 and Syn-4 demonstrated by our co-IP experiments (Fig. 3a) only occurs at FAs or also in other membrane domains. It is tempting to speculate that the fibronectin receptor Syn-4 would recruit Xcad-11 to FAs, but additional proteins may also be required. In future it will be interesting to search for such candidates and to analyse the molecular mechanisms of Xcad-11 recruitment to FAs in more detail.

\section{Discussion}

Our study reveals a novel function of Xcad-11 in mediating NC cell-substrate adhesion. Using high-resolution optical and atomic force microscopy, we present the first evidence that a classical cadherin localizes to FAs. Xcad-11 physically interacts with Syn-4, which mediates adhesion to fibronectin, whereas the cytoplasmic domain of Xcad-11 may bridge this complex to the cytoskeleton and drives cell migration. NCC may behave similarly to cancer cells ${ }^{34}$ in which cadherin-11 upregulation stimulates migration and invasiveness $8,9,10,35$. Since Xcad-11 localizes to FAs in different cell types, our results may uncover a general function of cadherin-11 in mediating cell-substrate adhesion and may contribute to better understanding cell migration and cell invasion in a variety of diseases.

\begin{abstract}
Methods
Constructs. Xcad-11, Xcad-11-EGFP, Xcad-11 deletion constructs (Xcad-11 $\Delta \mathrm{c}$ and Xcad-11 $\Delta \mathrm{e}$ ), Syn-4, FLAG-GFPSyn-4, GAP43-GFP, GAP43-mcherry and H2B-mcherry were described previously ${ }^{16,29,31,36}$. For Xcad-11 TM mut construct, Xcad-11 was amplified by mutagenesis PCR. The transmembrane domain of Xcad-11 was mutated by replacing two amino acids (V506P: Mut1-Fw, 5'-GTAA TTTTATTAGTGATTGTGCCCTTGTTTGTGACTCTGAGGA G-3'ㄹ Rev, 5'-CTC CTCAGAGTCACAAACAAGGGCACAATCACTAATAAAATTAC- $3^{\prime}$ and L507G: Mut2-Fw, 5'-GTGATTGTGCCCGGGTTTGTGACTCTGAGG-3'; Rev, $5^{\prime}$-CCTCAGAGTCACAAACCCGGGCACAATCAC-3'). For the Syn4Xcad 11 construct, the Syn-4 extracellular domain was amplified by PCR with NheI (Fw, $5^{\prime}$-GCTAGCATGAGTCCGACCCTGATGT-3') and BamHI (Rv, 5'-GGATCCTG TTCTCTGGAAGAATCCTTCC- $\left.3^{\prime}\right)$ restriction sites. The Syn- 4 extracellular domain was ligated with the transmembrane and the cytoplasmic domain of Xcad-11. For the Xcad-11 $\Delta \mathrm{e} \Delta \mathrm{c}$ construct, Xcad-11 $\Delta \mathrm{e}$ was digested with EcoRV and Acc65I to remove major parts of the cytoplasmic domain. Then, mutagenesis PCR was performed to include an in-frame EcoRI-restriction site using the following primers: Fw, 5'-GAAGAGGAAGATATCAAGCTTGGGCCC- ${ }^{\prime \prime}$; Rev, 5'-GGGCCCAAGCTTGATATCTTCCTCTTC- $3^{\prime}$. Xcad-11 and Syn- 4 morpholino antisense oligonucleotides (Xcad-11 MO, Syn-4 MO) were designed as previously characterized $^{16,31,36}$ and purchased from Gene Tools, LLC (Philomath, OR, USA) Vinculin-mCherry was published previously ${ }^{37}$.
\end{abstract}

Embryological methods and cell culture. Xenopus laevis embryos were obtained by in vitro fertilization and staged according to Nieuwkoop and Faber ${ }^{38}$. RNA for injection experiments was synthesized in vitro using mMessage mMachine Kit (Ambion Inc.; Norwalk, CT, USA). In all, 1 ng Xcad-11-EGFP, 100 pg of Xcad-11 Xcad-11 deletion constructs with exception of $\Delta \mathrm{e}(50 \mathrm{pg})$, Syn4Xcad11, GAP43GFP, H2B-mcherry, 250 pg Syn-4, 16 ng Xcad-11 MO and 16 ng Syn-4 MO were injected at the 8-16-cell stage. NC was dissected and cultured as previously described $^{16}$. For whole-mount in situ hybridization, embryos were fixed in MEMFA for $1 \mathrm{~h}$ at room temperature and in situ hybridization was carried out as described before ${ }^{39}$. Digoxingenin-labelled antisense RNA probes were synthesized using the Digoxingenin RNA labelling Kit (Roche, Basel, Switzerland) and a template DNA encoding AP2 (ref. 40). Results of at least three independent experiments were averaged and statistical significance was analysed by Student's $t$-test. Handling of animal cap explants was performed as described previously ${ }^{41}$. All constructs were transcribed in vitro into mRNA according to the manufacture's instruction (Ambion Inc.). Except for Xcad-11- $\Delta \mathrm{e}(500 \mathrm{pg}), 1 \mathrm{ng}$ of the RNA 
constructs were injected into both blastomeres of two-cell stage embryos. HeLa and MCF-7 cells were cultured in RPMI medium, while NIH 3T3 and HFF cells were cultured in DMEM. Both media contained 10\% FCS and 1\% penicillin/ streptomycin. HeLa, MCF-7 and NIH 3T3 cells were transfected with $2 \mu \mathrm{g}$ of Xcad-11-EGFP using JetPEI (Polyplus Transfection SA, Illkirch, France) or TransPass (New England Biolabs, Frankfurt) and incubated on fibronectin-coated glass chamber slides for $24-48 \mathrm{~h}$ before fixation.

Immunostaining. Cells were fixed with $4 \%$ paraformaldehyde in PBS for $10 \mathrm{~min}$. Cells were permeabilized by washing once with nonionic surfactant $(0.5 \%$ Triton-X 100 in PBS, PBST). Again, cells were washed twice with $0.1 \%$ PBST and blocked with $1 \%$ BSA/PBS solution for $30 \mathrm{~min}$. After washing once with PBS, cells were incubated overnight at $4{ }^{\circ} \mathrm{C}$ with anti $\beta$-catenin (1:200; BD Biosciences, USA), paxillin (1:200; BD Biosciences, USA), phosphorylated paxillin (Y118, Cell Signalling Technology, USA), cadherin-11 (1:100, 1B4 (ref. 42)), FAK, VASP, zyxin, N-cadherin, myc (9E10, undiluted; DSHB Hybridoma Bank, USA), Xcad-11 $\left(1: 200\right.$ (ref. 16)) or $\beta 1$-integrin (8C8, undiluted ${ }^{43}$ ) antibody. On the next day, cells were washed $3 \times$ with $0.1 \%$ PBST, blocked with $1 \%$ BSA/PBS for $30 \mathrm{~min}$ and incubated with secondary goat anti-mouse or goat anti-rabbit $\mathrm{Cy} 3$ or $\mathrm{Cy} 2$ antibody (1:400; Dianova GmbH, Hamburg) for $1 \mathrm{~h}$ at room temperature, followed by three washes with $0.1 \%$ PBST. To visualize the actin cytoskeleton, cells were incubated with Alexa Fluor 568 phalloidin red (dilution 1:50 in PBS) for $30 \mathrm{~min}$ at room temperature. Animal cap explants were cultured on BSA-coated Petri dishes and fixed in $4 \%$ paraformaldehyde buffered in PBS modified to amphibian osmolarity $\left(2.7 \mathrm{mM} \mathrm{KCl}, 0.15 \mathrm{mM} \mathrm{KH}_{2} \mathrm{PO}_{4}, 103 \mathrm{mM} \mathrm{NaCl}\right.$ and $0.7 \mathrm{mM} \mathrm{NaHPO}$, $\left.\mathrm{pH} 7.5\right)$ for $30 \mathrm{~min}$ at room temperature. For fluorescence immunohistochemistry, animal caps were permeabilized by incubation in $20 \% \mathrm{DMSO} / 80 \%$ methanol overnight at $-20^{\circ} \mathrm{C}$. After rehydration with descending methanol concentrations, the explants were washed extensively with APBS and incubated with blocking buffer $(20 \%$ horse serum in APBS) for $2 \mathrm{~h}$ at room temperature. Incubation with the primary antibodies mouse anti myc (9E10, undiluted supernatant) or anti XB-cadherin (6D5, undiluted supernatant) and rat anti- $\beta$-catenin (PGDS 7D12, undiluted supernatant; provided by R. Rupp) was performed overnight at $4{ }^{\circ} \mathrm{C}$. After washing extensively with APBS and reincubation with blocking buffer for $1 \mathrm{~h}$ at room temperature, the secondary antibody anti-mouse $\mathrm{Cy} 3$ and anti-rat Cy2 (Dianova; 1:200 in blocking buffer), respectively, was applied overnight at room temperature. The explants were counterstained with DAPI to visualize the nuclei, washed extensively in APBS, and finally embedded with Mowiol-DABCO.

Flipping assay. NCC explants were performed as previously described ${ }^{16}$. Several NCC explants were analysed and counted using a spinning disc confocal (Zeiss Cell Observer, $\times 63$ oil objective, AxioCam MRm camera) or fluorescent microscope (Leica DMIR2, $\times 63$ oil objective, Electronicbox Leica CTR MIC, Digital camera C4742-95-12 ERG). The precise position of each explant was recorded based on the $x / y$-stage positioning scale of the spinning disc microscope. Afterwards, the flipping assay was performed. The chamber-slide containing the NCC explants was completely filled with Danilchick's buffer. The chamber slide was then carefully lifted and dipped in a large vessel also containing Danilchick's buffer. The slide was then rotated by $180^{\circ}$ and held in an upside-down position for $15 \mathrm{~min}$, rotated back $180^{\circ}$ and carefully removed from the large vessel. After the flipping procedure, NCC explants were imaged at the same positions as before the assay. Finally, the percentage of NCC adhering to the substrate before and after the assay was calculated. At least three different explants were measured per condition. Statistical analysis was performed using the Student's $t$-test.

AFM-based SCFS. AFM-based SCFS experiments were performed using a NanoWizard II AFM (JPK) incorporating a JPK CellHesion module with an extended vertical pulling range of $100 \mu \mathrm{m}$. All measurements were performed at room temperature using tipless $\mathrm{V}$-shaped cantilevers with a nominal spring constant of $0.06 \mathrm{~N} \mathrm{~m}^{-1}$ (NP-O, Bruker). To facilitate cell capture, cantilevers were functionalized with concanavalin $\mathrm{A}^{44}$. A single-cell suspension was prepared from dissociated CNC explants as described above and pipetted into a plastic tissue culture Petri dish functionalized with fibronectin and containing $2 \mathrm{ml}$ pond water. The spring constant of the cantilever was determined in situ using the thermal noise method ${ }^{45}$. A single cell was then immobilized on the cantilever by approaching the cell with a contact force of $0.5 \mathrm{nN}$ for $3 \mathrm{~s}$. After a recovery period of 5-10 min, SCFS measurements were performed using a $1.5-\mathrm{nN}$ contact force, a $5 \mu \mathrm{m}$ per second approach and retract speed and a contact time ranging from 5 to $120 \mathrm{~s}$. Usually several force curve per contact time and cell were recorded. The cell-substrate contact position was changed after each force cycle. Maximum detachment forces were extracted from the recorded force curves using the JPK IP software.

Cell inversion procedure. For scanning the basal cell side of adherent cells by AFM, HeLa cells were transfected with Xcad-11-EGFP using FuGene HD (Roche) and incubated on fibronectin-coated PDMS for $16 \mathrm{~h}$. Afterwards, cells were fixed with $4 \%$ PFA and inverted according to a previously published protocol ${ }^{18}$. The basal cell side was scanned using a JPK Nanowizard II AFM mounted on a Zeiss Axiovert optical microscope. Imaging was performed in PBS in contact mode with gold-coated silicon nitride $\mathrm{V}$-shaped cantilevers (MLCT-C) with a spring constant of $0.06 \mathrm{~N} \mathrm{~m}^{-1}$ (Bruker). After AFM scanning, fluorescence images of cells were collected and correlated with the corresponding AFM height images. AFM images were processed using the JPK IP software and the fluorescence images were analysed with ImageJ (http://rsbweb.nih.gov/ij/).

Superresolution SIM. Superresolution structured illumination microscopy (SR-SIM) was performed with a nonserial Elyra PS.1 (www.zeiss.com) prototype using a $\times 63 / 1.40$ oil DIC objective and appropriate emission filters (transmission of $500-550 \mathrm{~nm}$ for $488 \mathrm{~nm}$, or double bandpass $420-545 \mathrm{~nm}$ and $575-640 \mathrm{~nm}$ for $561 \mathrm{~nm}$ excitation, respectively). Detection was performed with an Andor iXon 885 EMCCD camera. Twenty-five frames of raw data (five rotations and five shifts per rotation of the grid) were acquired and final images calculated with the Zeiss ZEN software. Multicolour SIM images were aligned by acquiring images of multifluorescent $200 \mathrm{~nm}$ beads mounted on slides and calculating colour shift with an algorithm implemented in the Zeiss software. Intensity profiles were measured with Zeiss ZEN software and exported to Microsoft Excel.

Co-immunoprecipitations. Co-immunoprecipitation experiments were performed in HEK293 obtained from ATCC and transfected with XtremeGENE HP (Roche) according to the manufacturer's instructions. Forty-eight hours after transfections,

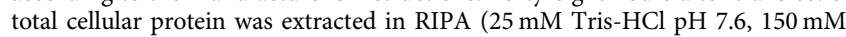
$\mathrm{NaCl}, 1 \% \mathrm{NP}-40,1 \%$ sodium deoxycholate, $0.1 \%$ SDS) with $5 \mathrm{mM}$ EDTA and $1 \times$ Halt Protease and Phosphatase Inhibitor Cocktail (Thermo Scientific) and immunoprecipitated for $2.5 \mathrm{~h}$ at room temperature using either the mouse anti-myc (9E10) or the mouse anti-flag (M2, Sigma) antibody. Immunoprecipitates were washed three times for $5 \mathrm{~min}$ in RIPA and eluted in reducing Laemmli buffer. Proteins were detected by western blot using the antibodies 9E10, M2 (1:4,000), or rabbit anti- $\beta$-catenin (Abcam, 1:4,000).

Microstripe assay. Fibronectin/BSA and fibronectin/laminin stripe patterns were produced on glass surfaces by microcontact printing ${ }^{46}$. For stamp fabrication, polydimethylsilfoxane (PDMS, Sylgard, www.dowcorning.com) was mixed with cross-linker at a ratio of 10:1, degassed in a vacuum chamber and added onto a micropatterned silicon master for $4 \mathrm{~h}$ at $60^{\circ} \mathrm{C}$. The PDMS stamp was peeled off the master, cleaned with $\mathrm{ddH}_{2} \mathrm{O}$, then with $100 \%$ ethanol and afterwards dried with nitrogen gas. BSA $\left(50 \mu \mathrm{g} \mu \mathrm{l}^{-1}\right)$ or laminin $\left(20\right.$ or $\left.50 \mu \mathrm{g} \mu \mathrm{l}^{-1}\right)$ solution was applied onto the PDMS stamp and incubated for $30 \mathrm{~min}$ at room temperature (BSA) or for $1 \mathrm{~h}$ at $37^{\circ} \mathrm{C}$ (laminin) in a humidified chamber. Subsequently, the stamp was washed with PBS and dried with nitrogen gas. At the same time, glass bottom Petri dishes (FD-35, http://www.wpiinc.com) were silanized using a 2\% solution of 3-glycidoxypropyl trimethoxysilane in ethanol ${ }^{47}$. The protein-coated PDMS was placed in the middle of the 3-glycidoxypropyl trimethoxysilane-coated glass dish and incubated for $30 \mathrm{~min}$ at room temperature. Afterwards, the position of the PDMS stamp was labelled on the back of the glass dish and the stamp was detached from the glass. For backfilling the remaining area, a PDMS chamber with a square central opening was placed on top of the $\mu \mathrm{CP}$-modified field, AlexaFluor568labelled fibronectin $\left(50 \mu \mathrm{g} \mathrm{ml}^{-1}\right)$ was pipetted into the chamber and incubated for $1 \mathrm{~h}$ in the dark at room temperature. Finally, the PDMS chamber was removed from the glass, washed with $10 \mathrm{ml}$ PBS and stored in PBS at $4{ }^{\circ} \mathrm{C}$. After transfection with Xcad-11-EGFP using FuGene HD, cells were incubated for $16 \mathrm{~h}$ at $37^{\circ} \mathrm{C}$. Afterwards, cells were trypsinized and reseeded onto microstripe patterns, incubated for $4 \mathrm{~h}$ and finally fixed with $4 \% \mathrm{PFA}$ for $30 \mathrm{~min}$ at room temperature. AFM imaging demonstrated that using a concentration of $20 \mu \mathrm{gl}^{-1}$ for laminin for stamp coating and $50 \mu \mathrm{g} \mathrm{ml}{ }^{-1}$ for fibronectin backfilling yielded microstripe patterns with minimal topographic variation.

Live-cell TIRF imaging. HeLa cells were grown in $25 \mathrm{~cm}^{2}$ culture flasks in RPMI medium until reaching $80 \%$ confluence. Afterwards, they were transfected with $10 \mu \mathrm{g} \mu \mathrm{l}^{-1}$ Xcad-11-EGFP and $2 \mu \mathrm{g} \mu \mathrm{l}^{-1}$ Vinculin-mCherry plasmid using FuGene HD. After overnight incubation at $37^{\circ} \mathrm{C}$, cells were reseeded on fibronectin-coated glass bottom Petri dish in $\mathrm{CO}_{2}$-independent Medium (Invitrogen). After $1 \mathrm{~h}$ TIRF images were acquired with an iMIC microscope (Till Photonics) and an APON 60XOTIRF objective (Olympus). All images were processed and analysed with ImageJ (http://rsbweb.nih.gov/ij/).

\section{References}

1. Thiery, J. P., Duband, J. L. \& Tucker, G. C. Cell migration in the vertebrate embryo: role of cell adhesion and tissue environment in pattern formation. Annu. Rev. Cell Biol. 1, 91-113 (1985).

2. Duband, J. L. et al. How do the migratory and adhesive properties of the neural crest govern ganglia formation in the avian peripheral nervous system? J. Cell. Biochem. 27, 189-203 (1985).

3. Aplin, A. E., Howe, A., Alahari, S. K. \& Juliano, R. L. Signal transduction and signal modulation by cell adhesion receptors: the role of integrins, cadherins, immunoglobulin-cell adhesion molecules, and selectins. Pharmacol. Rev. 50, 197-263 (1998). 
4. Thompson, R. N., Yates, C. A. \& Baker, R. E. Modelling cell migration and adhesion during development. Bull. Math. Biol. 74, 2793-2809 (2012).

5. Becker, S. F., Langhe, R., Huang, C., Wedlich, D. \& Kashef, J. Giving the right tug for migration: cadherins in tissue movements. Arch. Biochem. Biophys. 524, 30-42 (2012).

6. Takeichi, M. Morphogenetic roles of classic cadherins. Curr. Opin. Cell Biol. 7, 619-627 (1995).

7. Maitre, J. L. et al. Adhesion functions in cell sorting by mechanically coupling the cortices of adhering cells. Science 338, 253-256 (2012).

8. Bussemakers, M. J., Van Bokhoven, A., Tomita, K., Jansen, C. F. \& Schalken, J. A. Complex cadherin expression in human prostate cancer cells. Int. J. Cancer 85, 446-450 (2000)

9. Pishvaian, M. J. et al. Cadherin-11 is expressed in invasive breast cancer cell lines. Cancer Res. 59, 947-952 (1999).

10. Chang, S. K. et al. Cadherin-11 regulates fibroblast inflammation. Proc. Natl Acad. Sci. USA 108, 8402-8407 (2011).

11. Ding, X. et al. Cadherin-11 involves in synovitis and increases the migratory and invasive capacity of fibroblast-like synoviocytes of osteoarthritis. Int. Immunopharmacol. 26, 153-161 (2015).

12. Hadeball, B., Borchers, A. \& Wedlich, D. Xenopus cadherin-11 (Xcadherin-11) expression requires the Wg/Wnt signal. Mech. Dev. 72 101-113 (1998)

13. Mayor, R. \& Theveneau, E. The neural crest. Development 140, 2247-2251 (2013).

14. Carmona-Fontaine, C. et al. Contact inhibition of locomotion in vivo controls neural crest directional migration. Nature 456, 957-961 (2008).

15. Becker, S. F., Mayor, R. \& Kashef, J. Cadherin-11 mediates contact inhibition of locomotion during Xenopus neural crest cell migration. PLoS ONE 8, e85717 (2013).

16. Kashef, J. et al. Cadherin-11 regulates protrusive activity in Xenopus cranial neural crest cells upstream of Trio and the small GTPases. Genes Dev. 23, 1393-1398 (2009)

17. Kuo, J. C., Han, X., Hsiao, C. T., Yates, 3rd J. R. \& Waterman, C. M. Analysis of the myosin-II-responsive focal adhesion proteome reveals a role for beta-Pix in negative regulation of focal adhesion maturation. Nat. Cell Biol. 13, 383-393 (2011).

18. Gudzenko, T. \& Franz, C. M. Inverting adherent cells for visualizing ECM interactions at the basal cell side. Ultramicroscopy 128, 1-9 (2013).

19. Alfandari, D., Cousin, H., Gaultier, A., Hoffstrom, B. G. \& DeSimone, D. W. Integrin alpha5betal supports the migration of Xenopus cranial neural crest on fibronectin. Dev. Biol. 260, 449-464 (2003).

20. Zaidel-Bar, R., Milo, R., Kam, Z. \& Geiger, B. A paxillin tyrosine phosphorylation switch regulates the assembly and form of cell-matrix adhesions. J. Cell Sci. 120, 137-148 (2007).

21. Patel, S. D. et al. Type II cadherin ectodomain structures: implications for classical cadherin specificity. Cell 124, 1255-1268 (2006)

22. Huber, O., Kemler, R. \& Langosch, D. Mutations affecting transmembrane segment interactions impair adhesiveness of E-cadherin. J. Cell Sci. 112, 4415-4423 (1999).

23. Yasuda, S. et al. Activity-induced protocadherin arcadlin regulates dendritic spine number by triggering $\mathrm{N}$-cadherin endocytosis via TAO2beta and p38 MAP kinases. Neuron 56, 456-471 (2007)

24. Anastasiadis, P. Z. \& Reynolds, A. B. The p120 catenin family: complex roles in adhesion, signaling and cancer. J. Cell Sci. 113, 1319-1334 (2000).

25. Yap, A. S., Niessen, C. M. \& Gumbiner, B. M. The juxtamembrane region of the cadherin cytoplasmic tail supports lateral clustering, adhesive strengthening, and interaction with p120ctn. J. Cell Biol. 141, 779-789 (1998).

26. Boguslavsky, S. et al. p120 catenin regulates lamellipodial dynamics and cell adhesion in cooperation with cortactin. Proc. Natl Acad. Sci. USA 104, 10882-10887 (2007).

27. Rimm, D. L., Koslov, E. R., Kebriaei, P., Cianci, C. D. \& Morrow, J. S. Alpha $1(\mathrm{E})$-catenin is an actin-binding and -bundling protein mediating the attachment of F-actin to the membrane adhesion complex. Proc. Natl Acad. Sci. USA 92, 8813-8817 (1995).

28. Peng, X., Cuff, L. E., Lawton, C. D. \& DeMali, K. A. Vinculin regulates cell-surface E-cadherin expression by binding to beta-catenin. J. Cell Sci. 123, 567-577 (2010)

29. Borchers, A., David, R. \& Wedlich, D. Xenopus cadherin-11 restrains cranial neural crest migration and influences neural crest specification. Development 128, 3049-3060 (2001).

30. Woods, A. \& Couchman, J. R. Syndecan-4 and focal adhesion function. Curr. Opin. Cell Biol. 13, 578-583 (2001).

31. Matthews, H. K. et al. Directional migration of neural crest cells in vivo is regulated by Syndecan-4/Rac1 and non-canonical Wnt signaling/RhoA Development 135, 1771-1780 (2008).

32. Elenius, K., Salmivirta, M., Inki, P., Mali, M. \& Jalkanen, M. Binding of human syndecan to extracellular matrix proteins. J. Biol. Chem. 265, 17837-17843 (1990).
33. McFall, A. J. \& Rapraeger, A. C. Identification of an adhesion site within the syndecan-4 extracellular protein domain. J. Biol. Chem. 272, 12901-12904 (1997).

34. Theveneau, E. \& Mayor, R. Can mesenchymal cells undergo collective cell migration? The case of the neural crest. Cell Adh. Migr. 5, 490-498 (2011).

35. Tomita, K. et al. Cadherin switching in human prostate cancer progression. Cancer Res. 60, 3650-3654 (2000).

36. Munoz, R., Moreno, M., Oliva, C., Orbenes, C. \& Larrain, J. Syndecan-4 regulates non-canonical Wnt signalling and is essential for convergent and extension movements in Xenopus embryos. Nat. Cell Biol. 8, 492-500 (2006).

37. Carisey, A. et al. Vinculin regulates the recruitment and release of core focal adhesion proteins in a force-dependent manner. Curr. Biol. 23, 271-281 (2013).

38. Nieuwkoop, P. D. \& Faber, J. Normal Table of Xenopus laevis (Daudin) 2nd edn (North Holland Publishing Co., 1967).

39. Harland, R. M. In situ hybridization: an improved whole-mount method for Xenopus embryos. Methods Cell Biol. 36, 685-695 (1991).

40. Luo, T., Lee, Y. H., Saint-Jeannet, J. P. \& Sargent, T. D. Induction of neural crest in Xenopus by transcription factor AP2alpha. Proc. Natl Acad. Sci. USA 100, 532-537 (2003).

41. Korner, A. et al. Cell differentiation of pluripotent tissue sheets immobilized on supported membranes displaying cadherin-11. PLoS ONE 8, e54749 (2013).

42. McCusker, C., Cousin, H., Neuner, R. \& Alfandari, D. Extracellular cleavage of cadherin-11 by ADAM metalloproteases is essential for Xenopus cranial neural crest cell migration. Mol. Biol. Cell 20, 78-89 (2009).

43. Gawantka, V., Ellinger-Ziegelbauer, H. \& Hausen, P. Beta 1-integrin is a maternal protein that is inserted into all newly formed plasma membranes during early Xenopus embryogenesis. Development 115, 595-605 (1992).

44. Puech, P. H. et al. Measuring cell adhesion forces of primary gastrulating cells from zebrafish using atomic force microscopy. J. Cell Sci. 118, 4199-4206 (2005).

45. Hutter, J. L. \& Bechhoefer, J. Calibration of atomic-force microscope tips. Rev. Sci. Instrum. 64, 1868-1873 (1993).

46. Bernard, A., Renault, J. P., Michel, B., Bosshard, H. R. \& Delamarche, E. Microcontact printing of proteins. Adv. Mater. 12, 1067-1070 (2000).

47. Schlapak, R. et al. Glass surfaces grafted with high-density poly(ethylene glycol) as substrates for DNA oligonucleotide microarrays. Langmuir 22, 277-285 (2006).

\section{Acknowledgements}

We acknowledge discussions with Doris Wedlich, Martin Bastmeyer, Annette Borchers, Roberto Mayor, Carole LaBonne, Helene Cousin, Dietmar Gradl and Almut Köhler. Roberto Mayor provided us Syn-4 constructs and morpholinos. We thank Velia Schall and Ramona Ring for technical assistance. We are deeply grateful to Doris Wedlich and Martin Bastmeyer for their constant support. The work of M.B. is funded by the Karlsruhe School of Optics and Photonics (KSOP). G.A. and D.A. were supported by grants from National Institutes of Health USPHS (grant numbers F31-DE023275 to G.A. and RO1-DE016289 to D.A). S.F.B. received funding from the Deutsche Forschungsgemeinschaft (DFG) WE-1208-13-1. J.K.'s Young Investigator Group received financial support from the 'Concept for the Future' programme of Karlsruhe Institute of Technology within the framework of the German Excellence Initiative. This work was funded by a start-up grant of the Young Investigator Network support from the 'Concept for the Future' of the KIT (to J.K. and C.M.F.) and subproject E2.4 of the DFG-Center for Functional Nanostructures (C.M.F.). J.K., S.F.B., C.G., M.C.K. and C.M.F. were further supported by the Deutsche Forschungsgemeinschaft (DFG) through the DFG-FOR 1756 program (grants KA 4104/1-2 and FR 2107/2-1).

\section{Author contributions}

J.K. designed experiments, performed injections, NCC explants, flipping assays and drafted the manuscript. R.L. performed injections, NCC explants, cell culture, immunostainings, construct cloning, flipping assays and TIRF microscopy. C.M.F. designed AFM experiments, discussed the study and contributed text and performed SCFS experiments together with J.K. T.G. performed TIRF microscopy, cell inversion experiments, microcontact printing stripe assays and AFM imaging. C.G. performed TIRF microscopy, microcontact printing, AFM imaging and SCFS. M.B. performed SIM imaging. G.A. performed co-immunoprecipitations with the help and supervision of D.A S.F.B. performed injections, animal cap assays, NCC explants, TIRF microscopy and immunostainings. C.W. and M.C.K performed cell culture and immunostainings. All authors contributed to the final manuscript.

\section{Additional information}

Supplementary Information accompanies this paper at http://www.nature.com/ naturecommunication

Competing financial interests: The authors declare no competing financial interests 
Reprints and permission information is available online at http://npg.nature.com/ reprintsandpermissions/

How to cite this article: Langhe, R. P et al. Cadherin-11 localizes to focal adhesions and promotes cell-substrate adhesion. Nat. Commun. 7:10909 doi: $10.1038 /$ ncomms10909 (2016). (c) (i) This work is licensed under a Creative Commons Attribution 4.0 International License. The images or other third party material in this article are included in the article's Creative Commons license, unless indicated otherwise in the credit line; if the material is not included under the Creative Commons license, users will need to obtain permission from the license holder to reproduce the material. To view a copy of this license, visit http://creativecommons.org/licenses/by/4.0/ 